\title{
The Cardioprotective Role of Carvedilol, A Non-Selective $\beta$-Adrenoceptor Blocker, in Albino Rats with Type 2 Diabetes Mellitus
}

\author{
Selim M Abdel-Hakim* and Alaa-Eldeen R Abdel-Raheem** \\ Departments of Physiology* and Internal Medicine**, \\ Faculty of Medicine; El-Minia University
}

\begin{abstract}
The present work aimed to study the effects of carvedilol, a third generation $\beta$-blocker with antioxidant and $\alpha$-blocking activities, on glycemic control and cardioprotection in type 2 diabetes mellitus (DM) induced in rats by high fat diet (HFD). Seventy-two male albino rats (5 weeks of age) weighing 80-90g were exposed to dark/light cycle of 12/12 hours and randomly divided into six groups, each of 12 rats. Rats of Control Group were fed standard rat chow. Rats of HFD Group were fed HFD for induction of type 2 DM. Rats of the last 4 groups were the Carvedilol-S Group, the CarvedilolL Group, the Propranolol Group and the Aminoguanidine Group. They were fed HFD and treated with carvedilol (2mg/kg/day), carvedilol (20 mg/kg/day), propranolol (30 mg/kg/day) and aminguanidine (20 mg/kg/day) respectively All drugs were given orally by gavage in the morning. The animals were under feeding and subsequent treatments daily for 12 weeks. At the end of the experiment, rats were sacrificed, blood samples collected, centrifuged and sera were separated and stored at $-80^{\circ} \mathrm{C}$ till the time of analysis. The epididymal fat pads and one of the gastrocnemius muscles were excised, blotted dry and weighed and the weight ratio was recorded as the body composition index (BCI). Hearts were rapidly exposed and excised, washed in cold phosphate buffered saline (PBS), pH 7.4, blotted dry and weighed. The ratio between heart weight and body weight was calculated as heart weight index (HWI). Immediately, the hearts were flash-frozen in liquid nitrogen and kept frozen at $-80^{\circ} \mathrm{C}$ until the time of analysis. The parameters assayed were: serum lipid profile, lipid peroxides, insulin, glucose, myocardial lipid peroxides, superoxide dismutase (SOD) and catalase (CAT) enzymes, nitric oxide (NO) and oral glucose tolerence test (OGTT) where rats were fasted for 15 hours and glucose was given by gavage at a dose of $2 \mathrm{~g} / \mathrm{kg}$ then 6 blood samples were taken from retroorbital vien at half hour intervals. Results: HFD in male albino rats for 12 weeks induced type 2 DM. Dyslipidemic changes in these animals were observed as increased serum levels of total cholesterol (TC), low density lipoporotein-cholesterol (LDL-C), triglycerides (TGs) and decreased levels of high density lipoporotein-cholesterol (HDL-C). In addition, HFD induced oxidative and nitrative stress as evidenced by the increase in serum and myocardial levels of lipid peroxides and concomitant decrease in myocardial SOD and CAT and increased NO metabolites. HFD also induced cardiovascular complications as indicated by increased HWI in the HFD group. Administration of carvedilol in both dose levels had positive impact on glucose
\end{abstract}


homeostasis and lipid profile in HFD-fed animals. Propranolol, on the other hand, had an ameliorative effect on glucose metabolism but did not improve dyslipidemic changes induced by HFD and diabetes. In addition, administration of aminoguanidine had slight effect on glucose tolerance and lipid profile. No appreciable differences were observed among the four treated groups with regard to glucose homeostasis. The best effects of the drugs under investigation regarding prevention of dyslipidemia were attributed to large dose carvedilol followed by small dose and aminoguanidine while propranolol did not prevent development of dyslipidemia. Oxidative stress was antagonized to variable extents in the four drug treatment regimens. The best results were attributed to carvedilol in both dose levels. However, both propranolol and aminoguanidine showed antioxidant activities. All the three groups on $\beta$-blocker regimen displayed normalization of myocardial NO level. Conversely, aminoguanidine decreased this level dramatically. Conclusion: carvedilol showed dose-dependent improvements on glucose and lipid homeostasis, oxidative and nitrative stress. However, better effects were observed with the small dose on myocardial antioxidant activity. These effects might contribute but do not fully explain the dose-independent cardioprotection observed in the present study.

Key Words: High Fat Diet, Lipid Profile, Lipid Peroxides, $\beta$-blocker, Antioxidants, SOD, CAT, NO, Type 2 Diabetes Mellitus, Diabetic Cardiomyopathy, Cardioprotection, Carvedilol, Propranolol, Aminoguanidine.

\section{INTRODUCTION}

\begin{abstract}
Diabetes mellitus (DM), a complex metabolic disorder characterized by a state of chronic hyperglycemia. That complex disease condition has two major presentations, type 1 and type $2 \mathrm{DM}$. The incidence of that disease worldwide is progressively increasing mainly due to the increase in energy intake, leading to obesity. Because over $80 \%$ of all diabetic subjects have type 2 DM, which is usually diagnosed after the age of 40 years, the increase in the number of diabetic individuals implies an epidemic of type $2 \mathrm{DM}^{\mathbf{1}}$.

Cardiovascular disease is the major cause of morbidity and mortality in people with $\mathrm{DM}^{2}$. Coronary heart disease (CHD) and diabetic angiopathy, in particular, are major complications of that condition,
\end{abstract}

and over $50 \%$ of all patients die of $\mathrm{CHD}^{3}$. Clinical manifestations and pathophysiological mechanisms of diabetic angiopathy can be attributed mainly to the development of endothelial dysfunction. This can be manifested as alterations in the endothelial nitric oxide synthase (eNOS)/nitric oxide (NO) system, NO production or availability ${ }^{4}$ In addition, many interacting mechanisms may be involved in such endothelial dysfunction, hyperglycemia per $\mathrm{se}^{\mathbf{5}}$ or through the accumulation of advanced glycosylation end products ${ }^{6}$, increased oxidative stress leading to eNOS uncoupling $^{7}$ and NO-quenching by excess superoxide ${ }^{8}$, are thought to be responsible for this imbalance in NO metabolism. On the other hand, reactive oxygen species (ROS) have been implicated in cardiovascular 
diseases, including cardiomyopathy", and antioxidants have been demonstrated to provide partial protection in diabetes-induced cardiomyopathy ${ }^{10}$.

High fat diet (HFD) is a well known mechanism to induce type 2 DM by increasing the energy intake, leading to obesity and decreased sensitivity to insulin by down regulation of insulin receptors. HFD induce insulin resistance by reducing insulin mediated signaling pathways and inducing inflammatory cytokines that antagonize many of the actions of insulin ${ }^{1,11}$.

The $\beta$-adrenergic blockers are a group of sympatholytic drugs first introduced as anti-anginal agents ${ }^{12} \cdot \beta$ blockers are considered first choice or at least good alternatives to other drugs in cardiovascular as well as non-cardiovascular conditions ${ }^{\mathbf{1 3}}$. Carvedilol, a non selective $\beta$ adrenoceptor blocker with vasodilating properties, exerted primary though selective $\alpha-1$ blockade ${ }^{14}$, has been shown to posses a high degree of cardioproterction in experimental models of myocardial damage $^{\mathbf{1 5}}$. In addition, it was also shown to decrease low density lipoprotein (LDL) oxidation through its antioxidant properties ${ }^{\mathbf{1 6}}$.

\section{Aim of the Work:}

The aim of the present study was to evaluate the effects of carvedilol on glycemic control, insulin sensitivity and cardioprotection in an animal model of HFD-induced type 2 DM. An attempt to explore the possible mechanisms of these effects was considered.

\section{MATERIALS \& METHODS}

\section{I- Experimental Design:}

The animals used in the present study were male albino rats (5 weeks of age) weighing 80-90g. Animals were exposed to dark/light cycle of $12 / 12$ hours while food and water were available ad libitum except for the time before taking blood samples or performing oral glucose tolerance test (OGTT). The rats were randomly divided into six groups, each of 12 rats:

1. Control Group: In which animals were fed standard rat chow.

2. HFD Group: In which animals were fed high fat diet (HFD) for induction of type $2 \mathrm{DM}$ according to the method described by Susini and Lavau (1978) ${ }^{17}$. The HFD was prepared by mixing the following: Casein $30 \%$, beef fat $40 \%$, wheat flour $7 \%$, glucose $10 \%$, salt mixture $6 \%$, vitamin mixture 3\% (Vitamins: A $5000 \mathrm{IU} / \mathrm{g}, \mathrm{D}_{3} 100 \mathrm{IU} / \mathrm{g}, \mathrm{B}_{1} 1 \mathrm{mg} / \mathrm{g}, \mathrm{B}_{2}$ $1.25 \mathrm{mg} / \mathrm{g}, \mathrm{B}_{6} 0.5 \mathrm{mg} / \mathrm{g}, \mathrm{B}_{12} 5 \mu \mathrm{g} / \mathrm{g}, \mathrm{C}$ $15 \mathrm{mg} / \mathrm{g}, \mathrm{B}_{4} \mathrm{mg} / \mathrm{g}$, and $\mathrm{K}_{3} 0.75 \mathrm{mg} / \mathrm{g}$, in addition to amino acids: methionine $25 \mathrm{mg} / \mathrm{g}$ and lysine $20 \mathrm{mg} / \mathrm{g}$ ), and bran $4 \%$ and sufficient water to form a consistent paste. During the course of feeding, random blood samples were taken and subjected for glucose estimation. Rats with glucose level of $150 \mathrm{mg} / \mathrm{dl}$ were considered diabetic ${ }^{1}$.

3. Carvedilol-S Group: In which the rats were under HFD + carvedilol ( $2 \mathrm{mg} / \mathrm{kg} /$ day)

4. Carvedilol-L Group: In which the rats were under HFD + carvedilol (20 $\mathrm{mg} / \mathrm{kg} /$ day)

5. Propranolol Group: In which the rats were under HFD + Propranolol (30 mg/kg/day) 
6. Aminoguanidine Group: In which the rats were under HFD + Aminoguanidine (20 mg/kg/day)

All drugs were given orally by gavage in the morning. The doses of the drugs were chosen according to previous studies; carvedilol ${ }^{15}$, propranolol $^{18}$, and aminoguanidine ${ }^{19}$. The animals were under feeding and subsequent treatment daily for 12 weeks.

At the end of the experiment, blood samples were collected, centrifuged at $3500 \mathrm{rpm}$ for 10 minutes and sera were collected and stored at $-80^{\circ} \mathrm{C}$ till the time of analysis. For determination of fasting glucose level and during OGTT, blood samples were collected according to the method described by Van Herck et al. (1992) ${ }^{20}$.

\section{Tissue Isolation and Preparation:}

The epididymal fat pads and one of the gastrocnemius muscles were excised, blotted dry and weighed and the weight ratio was considered an index of body composition index $(\mathrm{BCI})^{\mathbf{2 1}}$. In addition, hearts were rapidly exposed and excised, washed in cold phosphate buffered saline (PBS), pH 7.4, blotted dry on a filter paper and weighed. The ratio between heart weight and body weight was calculated as heart weight index $(\mathrm{HWI})^{22}$, which is taken as an indicator of diabetic cardiomyopathy.Immediately, the hearts were flash-frozen in liquid nitrogen and kept frozen at $-80^{\circ} \mathrm{C}$ until the time of analysis. Prior to analysis, myocardial tissues were homogenized in cold PBS ( $\mathrm{pH} 7.4$ ), centrifuged and the supernatant was separated.

\section{III-Biochemical Assays:}

a) Serum glucose was determined enzymatically by the method introduced by Trinder (1969) ${ }^{\mathbf{2 3}}$.

b) Oral Glucose Tolerance Test (OGTT) was determined according to the method described by Kim et al. (1997) ${ }^{24}$. The animals were fasted for 15 hours before the test. Glucose was administrated by gavage at 0 time in a dose of $2 \mathrm{~g} / \mathrm{kg}$. blood samples were collected from retroorbital veins at 0 time and at $30,60,90,120$ and 180 minutes intervals after oral glucose loading. Glucose was determined enzymatically, in all samples for each animal, by the method introduced by Trinder (1969) ${ }^{23}$.

c) Serum Insulin concentration was assayed according to the principles of the method described by Clark and Hales (1994) ${ }^{25}$.

d)Serum Lipid Profile; Total Cholesterol (TC); High- \& LowDensity Lipoprotein-Cholesterol (HDL-C \& LDL-C) and Triglycerides (TGs) levels were determined by an enzymatic colorimetric methods described by Roeschlau et al. (1974) ${ }^{26}$, Burstein et al. (1970) ${ }^{27}$, Lopes-Virella et al. (1977) ${ }^{28}$, Friedewald et al. $(1972)^{29}$ and Bucolo and David, $(\mathbf{1 9 7 3})^{\mathbf{3 0}}$ respectively.

e) Lipid peroxidation was determined in serum and heart tissue homogenates according to the method described by Buege and Aust (1978) ${ }^{31}$.

f) Myocardial superoxide dismutase (SOD), catalase (CAT) activities and nitric oxide concentration (NO) were determined according to methods previously described by 
Nishikimi et al. (1972) ${ }^{32}$,Aebi (1984) $^{33}$ and Sun et al. (2003) ${ }^{34}$ respectively.

IV-Statistical Analysis:

Results were expressed as means \pm standard error of the mean (SEM) and were analyzed for statistically significant differences using unpaired $\mathrm{t}$ test to compare HFD and control groups and one-way analysis of variance (ANOVA) followed by the Tukey-Kramer post analysis test to compare all groups. $\mathrm{P}$ values less than 0.05 were considered significant.

\section{RESULTS}

1-Effect of High fat diet feeding (HFD) on body composition index (BCI) and its alteration by various treatments.

Feeding HFD to rats significantly increased BCI from $0.68 \pm 0.03$ to $1.10 \pm 0.047$. However, data illustrated in table (1) showed no significant difference between HFD group and other HFD-fed treated groups.

2-Effect of HFD on heart weight index (HWI) and its alteration by various treatments:

Feeding the rats HFD significantly increased the HWI from $3.48 \pm 0.11$ to $4.83 \pm 0.09$. On the other hand, carvedilol, propranolol and aminoguanidine significantly decreased HWI as compared to HFD group but insignificantly when compared to control group (table 1).

3. Effect of HFD feeding on fasting serum glucose level (FSG) and its alteration by various treatments:

HFD feeding induced a significant increase in fasting serum glucose levels in HFD group (156 \pm
$3.03 \mathrm{mg} / \mathrm{dl}$ ) when compared to the control group $(83.75 \pm 3.33 \mathrm{mg} / \mathrm{dl})$. Oral administration of carvedilol (in the 2 tested doses), propranolol and aminoguanidine caused significant reduction in FSG $(138 \pm 3.19$ and 137 $\pm 2.48,136 \pm 2.79$ and $143.27 \pm 1.51$ $\mathrm{mg} / \mathrm{dl}$ respectively) when compared to HFD group (table 2).

4. Effect of HFD feeding on oral glucose tolerance test (OGTT) and its alteration by various treatments:

HFD feeding in rats caused significant increase in the area under the curve (AUC) of the OGTT compared to control group. On the other hand, administration of carvedilol (in the 2 tested doses), propranolol and aminoguanidine caused significant decrease in the AUC of OGTT when compared to HFD group (table 3 and fig. 1).

5. Effect of HFD feeding fasting on serum insulin (FSI) and its alteration by various treatments:

Feeding rats HFD increased significantly fasting serum insulin concentration from $4.45 \pm 0.14$ to 7.04 $\pm 0.32 \mu \mathrm{U} / \mathrm{ml}$. On the other hand, treatment of HFD-fed animals with carvedilol, in the 2 tested doses, prevented that increase and tended to keep insulin levels near the normal values. In addition, administration of propranolol or aminoguanidine along with HFD feeding had ameliorative effect against this hyperinsulinaemia induced by HFD feeding (table 2).

6. Effect of HFD feeding on serum cholesterol level and its alteration by various treatments:

Induction of type 2 DM by HFD feeding significantly increased serum total cholesterol level as compared to control group. Administration of 
carvedilol, in the 2 tested dose levels or amonoguanidine, along with HFD, significantly decreased serum total cholesterol level to $79.56 \pm 5.15$, $66.58 \pm 2.94$ and $75.83 \pm 4.63 \mathrm{mg} / \mathrm{dl}$ respectively as compared to HFD group $(115.43 \pm 5.38 \mathrm{mg} / \mathrm{dl})$. Conversely, propranolol treatment insignificantly altered serum total cholesterol level compared with HFD group (table 4).

7. Effect of HFD feeding on serum High density lipoprotein cholesterol (HDL-C) level and its alteration by various treatments:

Induction of type 2 DM by HFD feeding significantly decreased serum HDL-C level as compared to control group. Concurrent administration of carvedilol, in the 2 tested dose levels, along with HFD significantly increased serum HDL-C level to 18.55 \pm 0.62 and $17.75 \pm 0.64 \mathrm{mg} / \mathrm{dl}$ respectively as compared to HFD group (12.15 $\pm 0.74 \mathrm{mg} / \mathrm{dl})$. Conversely, both propranolol and aminguanidine treatment insignificantly altered serum HDL-C level compared with HFD group. (table 5).

8. Effect of HFD feeding on serum Triglycerides (TGs) level and its alteration by various treatments:

Induction of type $2 \mathrm{DM}$, by HFD feeding significantly elevated serum TGs $(88.6 \pm 3.4 \mathrm{mg} / \mathrm{dl})$ as compared to control group $(60.5 \pm 4.8 \mathrm{mg} / \mathrm{dl})$. On the other hand, administration of carvedilol, in both tested dose levels, or propranolol significantly reduced serum TGs when compared to HFD group (table 4).

9. Effect of HFD feeding serum on Low density Lipoprotein Cholesterol $(L D L-C)$ level and its alteration by various treatments:
Induction of type 2 DM by HFD feeding significantly elevated serum LDL-C level from $23.67 \pm 2.6$ to 80.1 $\pm 4.1 \mathrm{mg} / \mathrm{dl}$ compared to control group. Administration of carvedilol (lower dose) or aminoguanidine along with HFD caused significant decrease of serum LDL-C level (45.5 \pm 1.8 and $47.25 \pm 0.8 \mathrm{mg} / \mathrm{dl}$ respectively) compared with HFD group. However these levels were still higher when compared to that of the control group. On the other hand, the large dose of carvedilol tended to normalize serum LDL-C level $(36.1 \pm 2.1 \mathrm{mg} / \mathrm{dl})$. Conversely, propranolol treatment insignificantly changed serum LDL-C level $(70.67 \pm 3.8 \mathrm{mg} / \mathrm{dl})$ when compared to HFD group (table 5).

10. Effect of HFD feeding on serum and myocardial thiobarbituric acid reactive substances (TBARS) level and its alteration by various treatments:

Induction of type 2 DM by HFD significantly increased the level of TBARS in both serum (from $2.81 \pm$ 0.12 to $4.41 \pm 0.11 \eta \mathrm{mol} / \mathrm{ml}$ ) and myocardium (from $2.64 \pm 0.2$ to 10.7 $\pm 0.4 \eta \mathrm{mol} / \mathrm{mg}$ wet tissue). On the other hand, treatment of the HFD rats with the tested drugs significantly prevented this increase in serum and myocardial TBARS (table 6).

11. Effect of HFD feeding on mycardial superoxide dismutase (SOD) and catalase (CAT) activities and its alteration by various treatments:

Induction of type 2 DM by feeding HFD induced significant reduction in myocardial SOD activity when compared to control group. On the contrary, carvedilol in its small dose, tended to significantly 
ameliorate that effect on SOD decreased activity as a result of HFD feeding. All of the other groups showed insignificant alteration regarding myocardial SOD activity when compared to HFD group. Neither HFD feeding nor all pharmacological interventions induced any significant change in myocardial CAT activity (table 7).
12. Effect of HFD feeding on myocardial total NO level and its alteration by various treatments:

Induction of type $2 \mathrm{DM}$ by HFD feeding resulted in significant increase in myocardial total NO level. Administration of carvedilol, propranolol and aminoguanidine prevented this increase (table 8 ).

Table (1): Effect of HFD on body composition index (BCI), Heart Weight Index (HWI) and its alteration by various treatments

\begin{tabular}{|l|c|c|}
\hline \multicolumn{1}{|c|}{ GROUP } & $\begin{array}{c}\text { BCI } \\
\text { (epidid fat/ gastrocnemius } \\
\text { mass g/g) }\end{array}$ & $\begin{array}{c}\text { HWI } \\
\text { (heart weight/body weight } \\
\text { mg/g) }\end{array}$ \\
\hline Control & $\mathbf{0 0 . 6 8} \pm \mathbf{0 . 0 3}$ & $\mathbf{3 . 4 8} \pm \mathbf{0 . 1 1}$ \\
\hline HFD & $\mathbf{0 1 . 1 0} \pm \mathbf{0 . 0 4 7 ^ { \mathrm { a } }}$ & $4.83 \pm \mathbf{0 . 0 9}$ \\
\hline Carvedilol-S & $\mathbf{0 0 . 9 7} \pm \mathbf{0 . 0 8}$ & $\mathbf{3 . 8 8} \pm \mathbf{0 . 0 5}$ \\
\hline Carvedilol-L & $\mathbf{0 1 . 1 0} \pm \mathbf{0 . 0 7}$ & $4.20 \pm \mathbf{0 . 1 0}$ \\
\hline Propranolol & $\mathbf{0 0 . 9 6} \pm \mathbf{0 . 0 7}$ & $4.30 \pm \mathbf{0 . 0 7}$ \\
\hline Aminoguanidine & $\mathbf{0 1 . 0 0} \pm \mathbf{0 . 0 8}$ & $4.03 \pm \mathbf{0 . 1 2}$ \\
\hline
\end{tabular}

Data represent the mean \pm SEM of 12 observations. $a=$ significant from control group at $p<0.05$ and $b=$ significant from HFD group at $p<0.05$. HFD $=$ high fat diet, $B C I=$ body composition index, HWI = heart weight index and Epidid = epididymal,

Table (2): Effect of HFD on Fasting Serum Glucose (FSG), Fasting Serum Insulin (FSI) and its alteration by various treatments

\begin{tabular}{|c|c|c|}
\hline GROUP & $\begin{array}{l}\text { Fasting Serum Glucose } \\
\text { (FSG) }(\mathrm{mg} / \mathrm{dl})\end{array}$ & $\begin{array}{c}\text { Fasting Serum Insulin (FSI) } \\
(\mu \mathrm{U} / \mathrm{ml})\end{array}$ \\
\hline Control & $083.75 \pm 3.33$ & $4.45 \pm 0.14$ \\
\hline HFD & $156.00 \pm 3.03^{a}$ & $7.04 \pm 0.31^{a}$ \\
\hline Carvedilol-S & $138.00 \pm 3.19^{\mathrm{a}, \mathrm{b}}$ & $5.12 \pm 0.25^{b}$ \\
\hline Carvedilol-L & $137.00 \pm 2.48^{\mathrm{a}, \mathrm{b}}$ & $4.91 \pm 0.14^{b}$ \\
\hline Propranolol & $136.00 \pm 2.79^{a, b}$ & $5.36 \pm 0.40^{b}$ \\
\hline Aminoguanidine & $143.27 \pm 1.51^{\mathrm{a}, \mathrm{b}}$ & $5.05 \pm 0.38^{b}$ \\
\hline
\end{tabular}

Data represent the mean \pm SEM of 12 observations. $a=$ significant from control group at $p<0.05, b=$ significant from HFD group at $p<0.05$. HFD $=$ high fat diet. 
Table (3): Effect of HFD on the area under the curve (AUC) of oral glucose tolerense test (OGTT) and its alteration by various treatments

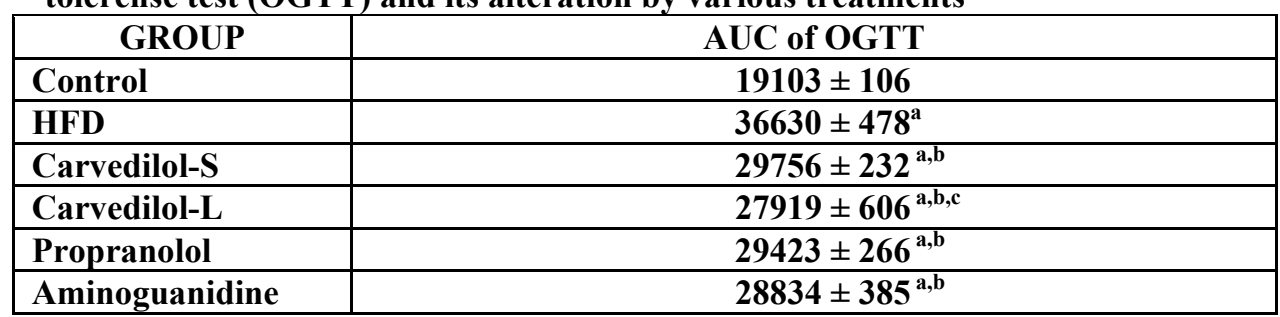

Data represent the mean \pm SEM of 12 observations. $a=$ significant from control group at $p<0.05, b=$ significant from HFD group at $p<0.05 c=$ significant from crvidilol-S group at $p<0.05$. AUC = area under the curve, OGTT = oral glucose tolerance test.

Figure (1) : Effect of HFD feeding on OGTT and its modulation by various treatments

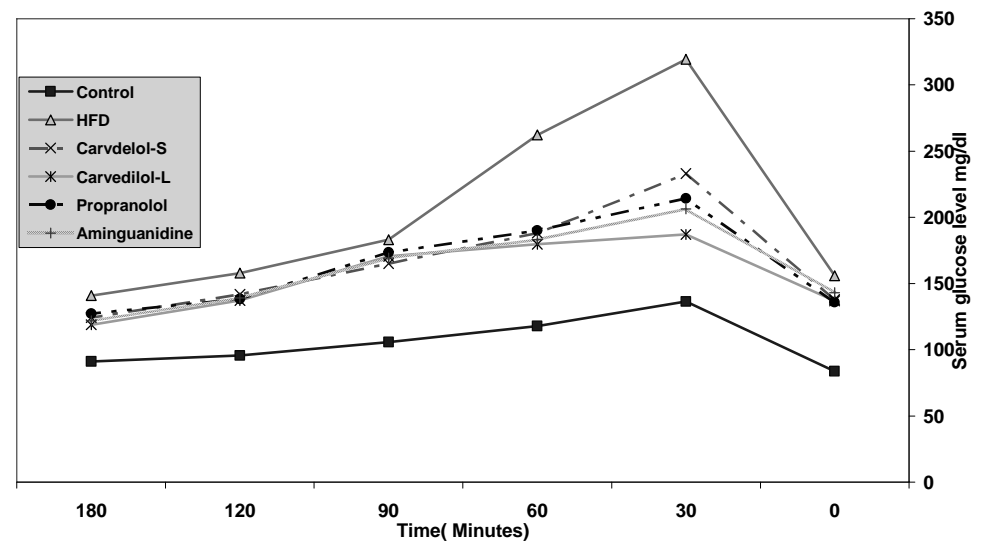

Table (4): Effect of HFD on Serum Total Cholesterol, Triglycerides level and its alteration by various treatments.

\begin{tabular}{|l|c|c|}
\hline \multicolumn{1}{|c|}{ GROUP } & Serum TC (mg/dl) & Serum TGs (mg/dl) \\
\hline Control & $\mathbf{0 5 6 . 5 9} \pm \mathbf{3 . 0 2}$ & $\mathbf{6 0 . 5} \pm 4.8$ \\
\hline HFD & $115.43 \pm 5.38^{\mathrm{a}}$ & $\mathbf{8 8 . 6} \pm 3.4^{\mathrm{a}}$ \\
\hline Carvedilol-S & $\mathbf{0 7 9 . 5 6} \pm \mathbf{5 . 1 5}^{\mathrm{a}, \mathrm{b}}$ & $\mathbf{6 6 . 5} \pm 3.3^{\mathrm{b}}$ \\
\hline Carvedilol-L & $\mathbf{0 6 6 . 5 8} \pm 2.94^{\mathrm{b}}$ & $\mathbf{6 5 . 9}^{\mathrm{b}} \pm \mathbf{1 . 6}^{\mathrm{b}}$ \\
\hline Propranolol & $\mathbf{1 0 5 . 9 8} \pm \mathbf{4 . 6 4}^{\mathrm{a}}$ & $\mathbf{6 9 . 4} \pm 3.3^{\mathrm{b}}$ \\
\hline Aminoguanidine & $\mathbf{0 7 5 . 8 3} \pm \mathbf{4 . 6 3}^{\mathrm{a} . \mathrm{b}}$ & $\mathbf{8 6 . 9} \pm 4.8$ \\
\hline
\end{tabular}

Data represent the mean \pm SEM of 12 observations. $a$ = significant from control group at $p<0.05, b=$ significant from HFD group at $p<0.05$. TC = total cholesterol, TGs = triglycerides. 
Table (5): Effect of HFD on Serum High and Low Denisty Lipoprotein Cholesterol (HDL-C; LDL-C) levels and its alteration by various treatments.

\begin{tabular}{|l|c|c|}
\hline \multicolumn{1}{|c|}{ GROUP } & Serum HDL-C (mg/dl) & Serum LDL-C (mg/dl) \\
\hline Control & $\mathbf{2 0 . 7 8} \pm \mathbf{0 . 9 1}$ & $\mathbf{2 3 . 6 7} \pm \mathbf{2 . 6}$ \\
\hline HFD & $\mathbf{1 2 . 1 5} \pm \mathbf{0 . 7 4}$ & $\mathbf{8 0 . 1} \pm \mathbf{4 . 1}$ \\
\hline Carvedilol-S & $\mathbf{1 8 . 5 5} \pm \mathbf{0 . 6 3}$ & $\mathbf{4 5 . 5}^{\mathbf{b}} \pm \mathbf{1 . 8}^{\mathbf{a}, \mathbf{b}}$ \\
\hline Carvedilol-L & $\mathbf{1 7 . 7 5} \pm \mathbf{0 . 6 4}$ & $\mathbf{3 6 . 1} \pm \mathbf{2 . 1}^{\mathbf{b}}$ \\
\hline Propranolol & $\mathbf{1 3 . 6 7} \pm \mathbf{0 . 4 8}$ & $\mathbf{7 0 . 6 7}^{\mathbf{b}} \mathbf{3 . 8}^{\mathbf{a}}$ \\
\hline Aminoguanidine & $\mathbf{1 3 . 4 1} \pm \mathbf{0 . 8 1}$ & $\mathbf{4 7 . 2 5}^{\mathbf{b}} \mathbf{0 . 8 ^ { \mathbf { a , b } }}$ \\
\hline
\end{tabular}

Data represent the mean \pm SEM of 12 observations. $a$ = significant from control group at $p<0.05, b=$ significant from HFD group at $p<0.05$. HDL-C $=$ high density lipoprotein cholesterol, $\mathrm{LDL}-\mathrm{C}=$ low density lipoprotein cholesterol.

Table (6): Effect of HFD on Serum and myocardial Thiobarbituric Acid Reactive Substances (TBARS) and its alteration by various treatments.

\begin{tabular}{|c|c|c|}
\hline GROUP & $\begin{array}{l}\text { Serum TBARS } \\
(\eta \mathrm{mol} / \mathrm{ml})\end{array}$ & $\begin{array}{l}\text { Myocardial TBARS } \\
\text { ( } \eta \mathrm{mol} / \mathrm{mg} \text { wet tissue) }\end{array}$ \\
\hline Control & $2.81 \pm 0.12$ & $02.64 \pm 0.2$ \\
\hline HFD & $4.41 \pm 0.11^{a}$ & $10.70 \pm 0.4^{a}$ \\
\hline Carvedilol-S & $2.43 \pm 0.09^{b}$ & $03.54 \pm 0.3^{b}$ \\
\hline Carvedilol-L & $2.74 \pm 0.07^{b}$ & $02.24 \pm 0.2^{b}$ \\
\hline Propranolol & $3.19 \pm 0.21^{b}$ & $04.07 \pm 0.2^{b}$ \\
\hline Aminoguanidine & $2.74 \pm 0 . .07^{b}$ & $03.05 \pm 0.3^{b}$ \\
\hline
\end{tabular}

Data represent the mean \pm SEM of 12 observations. $a$ = significant from control group at $p<0.05, b=$ significant from HFD group at $p<0.05$. TBARS = thiobarbituric acid reactive substances.

Table (7): Effect of HFD on myocardial superoxide dismutase and catalase activities and its alteration by various treatments.

\begin{tabular}{|l|c|c|}
\hline \multicolumn{1}{|c|}{ GROUP } & $\begin{array}{c}\text { Myocardial SOD activity } \\
\text { (U/mg wet tissue) }\end{array}$ & $\begin{array}{c}\text { Myocardial CAT activity } \\
\text { (U/mg wet tissue) }\end{array}$ \\
\hline Control & $\mathbf{1 0 . 0 0} \pm \mathbf{0 . 4 5}$ & $\mathbf{0 . 1 7} \pm \mathbf{0 . 0 2 0}$ \\
\hline HFD & $\mathbf{0 6 . 2 1} \pm \mathbf{0 . 2 0}$ & $\mathbf{0 . 1 4} \pm \mathbf{0 . 0 0 6}$ \\
\hline Carvedilol-S & $\mathbf{0 8 . 7 4} \pm \mathbf{0 . 5 9}^{\mathbf{b}}$ & $\mathbf{0 . 1 7} \pm \mathbf{0 . 0 0 9}$ \\
\hline Carvedilol-L & $\mathbf{0 7 . 5 3} \pm \mathbf{0 . 2 0}^{\mathbf{a}}$ & $\mathbf{0 . 1 6} \pm \mathbf{0 . 0 1 0}$ \\
\hline Propranolol & $\mathbf{0 7 . 0 8}^{\mathbf{a}} \mathbf{\mathbf { 0 . 5 2 } ^ { \mathbf { a } }}$ & $\mathbf{0 . 1 7} \pm \mathbf{0 . 0 1 1}$ \\
\hline Aminoguanidine & $\mathbf{0 7 . 4 4} \pm \mathbf{0 . 0 5}^{\mathbf{a}}$ & $\mathbf{0 . 1 7} \pm \mathbf{0 . 0 1 5}$ \\
\hline
\end{tabular}

Data represent the mean \pm SEM of 12 observations. $a$ = significant from control group at $p<0.05, b=$ significant from HFD group at $p<0.05$. SOD $=$ superoxide dismutase, $C A T=$ catalase . 
Table (8): Effect of HFD on myocardial total NO level and its alteration by various treatments.

\begin{tabular}{|l|c|}
\hline GROUP & Myocardial Total NO $(\eta \mathbf{m o l} / \mathbf{m g}$ wet tissue) \\
\hline Control & $\mathbf{4 . 1 6} \pm \mathbf{0 . 2 9}$ \\
\hline HFD & $\mathbf{6 . 4 2} \pm \mathbf{0 . 2 9}$ \\
\hline Carvedilol-S & $\mathbf{3 . 8 1} \pm \mathbf{0 . 1 9}$ \\
\hline Carvedilol-L & $\mathbf{3 . 4 3} \pm \mathbf{0 . 2 5}$ \\
\hline Propranolol & $\mathbf{4 . 0 3} \pm \mathbf{0 . 2 1}$ \\
\hline Aminoguanidine & $\mathbf{2 . 1 6} \pm \mathbf{0 . 1 7}$ \\
\hline
\end{tabular}

Data represent the mean \pm SEM of 12 observations. $a=$ significant from control group at $p<0.05, b=$ significant from HFD group at $p<0.05$. $N O=$ nitric oxide.

\section{DISCUSSION}

Diabetes mellitus is one of the most common disease conditions worldwide ${ }^{35}$. The disease can be defined as a complex metabolic disorder characterized by chronic hyperglycemia which is a cardinal $\operatorname{sign}^{36}$, altered metabolism, and high risk of cardiovascular complications ${ }^{37}$. Macrovascular complications including coronary heart disease (CHD), diabetic cardiomyopathy (DCM), and hypertension ${ }^{38}$.

In the present study, administration of small and large doses of carvedilol as well as propranolol in the HFD-fed rats had protective effects against development and progression of diabetes in these rats. Fasting as well as post load glucose levels in animals treated with these $\beta$-blockers were significantly lower in the treated groups than the HFD group. On the other hand, aminoguanidine, despite having similar effects, these were of lower magnitude. Moreover, all animals treated with any of the drugs in the current study showed significant improvements in glucose disposal after an oral glucose load at different time points. Best results in this regard were attributed to large dose carvedilol followed by aminoguanidine, propranolol, and small dose carvedilol, respectively, when compared to HFD group.

Fasting hyperinsulinemia is a characteristic feature in insulin resistant states including obesity and type $2 \mathrm{DM}^{39}$. In the present work, administration of different agents had positive impact on fasting insulin levels. Best results in this regard were observed with large dose carvedilol followed by aminoguanidine, small dose carvedilol, and propranolol, respectively.

Carvedilol is well known for its antioxidant activity $^{\mathbf{4 0}}$ and propranolol is extensively metabolized in the liver with one of its major metabolites being a potent antioxidant ${ }^{41}$. Nevertheless, aminoguanidine is well documented for its antioxidant properties ${ }^{42}$. In addition, being an $\alpha_{1-}$ blocker, carvedilol can decrease peripheral vascular resistance; an action that might be expected to increase glucose disposal and decrease insulin resistance ${ }^{43}$. In support to this hypothesis are various reports from 
studies on $\alpha_{1}$-blockers. Prazocin and doxazocin, as $\alpha_{1}$-blockers, were reported to decrease insulin resistance by enhancing glucose disposal in peripheral tissues ${ }^{44}$. The results of the present study are in agreement with previous reports of other investigators on carvedilol ${ }^{45,46}$, propranolol ${ }^{47}$, and aminoguanidine ${ }^{48}$. However, in a recent study involving hyperthyroidism-induced insulin resistance, propranolol was reported to decrease fasting glucose but had no effect on AUC of OGTT ${ }^{46}$.

On the other hand, carvedilol was reported to increase nitric oxide availability which may be due to its antioxidant activity ${ }^{49}$. In addition, $\beta$ blockers may inhibit the adrenoceptor mediated activation of p38 mitogenactivated protein kinases (MAPK) pathway $^{50}$, which may be an indirect antioxidant effect. These proposed mechanisms may be strengthened, at least in part, by the results of the Aminoguanidine Group in the present study. Aminoguanidine, an inhibitor of iNOS and of well documented antioxidant $\operatorname{properties}^{19}$, was accompanied with improvements in glucose homeostasis parameters when compared to HFD Group.

In the present study, carvedilol, in two dose levels, showed preferential effects against atherogenic dyslipidemic changes-induced by HFD in rats. Animals under carvedilol treatments showed prophylaxis against increases in levels of TC, TGs, and LDL-C. Conversely, HDL-C levels were favorably elevated due to carvedilol administration in a doseindependent manner. However, a dose-dependent but non-significant difference was noticed in TC and
LDL-C levels. These effects of carvedilol are in agreement with previous reports $^{51-53}$ in clinical trials of carvedilol in comparison to other $\beta$ blockers. However, reports by other authors indicated that carvedilol had no significant effects on lipid profile $^{54}$.

On the other hand, dyslipidemic changes due to HFD were not antagonised by propranolol in the present study. The effects of aminoguanidine on lipid profile were not different from carvedilol regarding TC and LDL-C. On the other hand, lower effects on serum TGs and HDLC were observed.

In the present study, carvedilol in both doses, showed potent antioxidant activity in serum as well as myocardial tissue of rats fed HFD. Its antioxidant activity was greater than that of propranolol or aminoguanidine.

An obvious trend to inhibit lipid peroxidation was shown in the present study with carvedilol administration. Moreover, a tendency to normalize level of activity of endogenous antioxidant machinery was also evident in animals treated with carvedilol in both doses. The antioxidative, antihypertensive and antiproliferative activities of carvedilol were supported by many authors as possible mechanisms ${ }^{\text {55-57 }}$.

On the other hand, surprisingly, propranolol administration in rats fed HFD showed significant antioxidant activity. A recent report described potent antioxidant activity of 4hydroxypropranolol, a major active metabolite of propranolol ${ }^{41}$. In addition, propranolol itself might have an indirect antioxidant effect through 
blockage of $\beta$-adrenoceptor mediated activation of p38 MAPK pathway ${ }^{49}$. Moreover, tendency to normalize myocardial activities of SOD and CAT has been shown to variable degrees in the present study in Propranolol and Aminoguanidine Groups.

Nitric oxide is a very important biological mediator that is vital to normal physiological function; however, increased levels are considered toxic and a source of nitrative stress ${ }^{\mathbf{5 8 , 5 9}}$. In the present study, NO metabolites were decreased in animals of the Carvedilol Groups compared to Propranolol and HFD Groups. These results are in agreement with previous observations. Carvedilol was previously reported to decrease myocardial iNOS expression in patients with dilated cardiomyopathy ${ }^{\mathbf{6 0}}$ and in a model of diet-induced atherosclerosis where it also enhanced the activity of eNOS and increased NO bioavailability ${ }^{61}$.

In the present study, myocardial hypertrophy caused in rats rendered diabetic by consumption of HFD was ameliorated by carvedilol in a dose independent manner. On the other hand, propranolol significantly reduced myocardial hypertrophy in these animals, but with a protective degree lower than that conferred by small dose carvedilol. Significant cardioprotection was also seen in animals treated with aminoguanidine. However, normalization of heart size and almost complete protection was observed only in the Carvedilol-S Group.

However, in the present study, the degree of protection observed with the small dose of carvedilol was higher than with the large dose or propranolol. Moreover, the antihypertrophic effects of large dose carvedilol as well as propranolol were only slight despite being significant. This would suggest that cardiac protection in the present study, to a large extent, is dependent on other factors besides the cardioprotective effects of $\beta$-blockade. The degree of $\beta$-blockade with the large dose carvedilol is for sure higher than with the small dose. In addition, propranolol, a non-selective $\beta$-blocker induced only a slight improvement. Other mechanisms should exist to explain these differential effects.

The antioxidant activity of carvedilol (and its metabolites) is much higher than that of propranolol as illustrated by results of the current study. Both myocardial and serum levels of oxidative stress parameters were lower in Carvedilol Groups. Also, myocardial tissue antioxidant defence systems (SOD and CAT) were increased at least in the Carvedilol-S Group.

The results of the present study are in agreement with other authors who found preferential effects of carvedilol in amelioration of ventricular hypertrophy. The protective effects of carvedilol were attributed to better glycemic control and prevention of myocardial remodelling. Carvedilol decreased heart weight to the body weight ratio as well as decreased cardiac extracellular matrix proteins (ECMPs) such as collagen, laminin, and fibronectin ${ }^{62}$.

In conclusion: carvedilol showed dose-dependent improvements on glucose and lipid homeostasis, 
oxidative and nitrative stress. However, better effects were observed with the small dose on myocardial antioxidant activity. These effects might contribute but do not fully explain the dose-independent cardioprotection observed in the present study. The anti-proliferative or antioxidative effects of carvedilol were suggested as possible mechanisms.

\section{REFERENCES}

1. Laakso, M. (2001): Cardiovascular Disease in Type 2 Diabetes: Challenge for Treatment and Prevention. $\boldsymbol{J}$. Intern. Med., 249: 225-235.

2. Jones, $K$. and Dewan, $K$. (2003): Type 2 diabetes mellitus in adolescence: Lipid and cardiovascular risk factors. Curr. Diabetes Rep., 3(3): 255-262.

3. Landray, M.; Toescu, V. and Kendall, M. (2002): The Cardioprotective Role of BetaBlockers in Patient with Diabetes Millitus. J. Clin. Pharm. Ther., 27: 233-242.

4. Santilli, F.; Cipollone, F.; Mezzetti, A. and Chiarelli, F. (2004): The Role of Nitric Oxide in the Development of Diabetic Angiopathy Horm. Metab. Res., 36: 319-335.

5. Brands, M. and Hopkins, T. (1996): Poor Glycemic Control Induces Hypertension in Diabetes Mellitus. Hypertension, 27: 735739.

6. Asbun, J. and Villarreal, F. (2006): The pathogenesis of Myocardial Fibrosis in the setting of Diabetic Cardiomyopathy.
J.Amm. Coll. Cardiol., 47: 693700.

7. Aydin, A.; Orhan, H.; Sayal, A.; Ozata, M.; Sahin, G. and Isimer, A. (2001): Oxidative Stress and Nitric Oxide Related Parameters in Type II Diabetes Mellitus: Effect of Glycemic Control. Clin. Biochem., 34: 6570.

8. Zou, M.; Cohen, R. and Ullrich, V. (2004): Peroxynitrite and Vascular Endothelial Dysfunction in Diabetes Millitus. Endothelium, 11: 89-97.

9. Kono, Y.; Nakamura, K.; Kimura, H.; Nishii, N.; Watanabe, A.; Banba, K.; Miura, A.; Nagase, S.; Sakuragi, S.; Kusano, K.; Matsubara, $H$. and Ohe, T. (2006): Elevated Levels of Oxidative DNA Damage in Serum and Mycardium of Patients with Heart Failure. Circ. J., 70: 1001-1005.

10. Kaul, N.; Siveski-Iliskovic, N.; Hill, M.; Khaper, N.; Seneviratne, C. and Singal, $P$. (1996): Probucol Treatment Reverses Antioidant and Functional Deficit in Diabetic Cardiomyopathy. Mol. Cell Biochem., 160: 283-288.

11. Wannamethee, S.; Shaper, A.; and Walker, M. (2005): Overweight and obesity and weight changes in middle aged men: Impact on cardiovascular disease and diabetes. $\boldsymbol{J}$. Epidemiol. Community Health, 59: 134-139.

12. Gerber, J. and Nies, A. (1985): Beta-Adrenergic Blocking Drugs. Annu. Rev. Med., 36: 145-164.

13. Lopez-Sendon, J.; Swedberg, K.; McMurray, J.; Tamargo, 
J.; Maggioni, A.; Dargle, H.; Tendra, M.; Waagstein, F.; Kjekshus, J.; Lechat, P. and Top-Peder, C. (2004): Expert Consensus Document on BetaAdrenergic Receptor Blockers. Eur. Heart J., 23: 1341-1362.

14. Stroe, A. and Gheorghiade, $M$. (2004): Carvedilol: BetaBlockade and beyond. Rev. Cardiovsc. Med., 5 (Suppl. 1): S18-S27.

15. Watanabe, K.; Ohta, Y.; Nakazawa, M.; Higuchi, H.; Hasegawa, G.; Natio, M.; Fuse, K.; Ito, M.; Hirono, S.; Tanabe, N.; Hanawa, H.; Kato, K.; Kodama, M. and Aizawa, Y. (2000): Low Dose Carvedilol Inhibits Progression of Heart Failure in Rats with Dilated Cardiomyopathy. $\quad \boldsymbol{B r}$. J. Pharmacol., 130: 1489-1495.

16. Yue, T.; Wang, X.; Gu, J.; Ruffolo, R. and Feuertein, G. (1995): Carvedilol, a New Vasodilating Beta-Adrenoceptor Blocker, Inhibits Oxidation of Low-Density Lipoprotein by Vascular Smooth Muscle Cells and Prevents Leukocyte Adhesion to Smooth Muscle Cells. J. Pharmacol. Exp. Ther., 273: 1442-1449.

17. Susini, C. and Lavau, M. (1978): In-Vitro and In-Vivo Responsiveness of Muscle and Adipose Tissue to Insulin in Rats Rendered Obese by High-Fat Diet. Diabetes, 27: 114-120.

18. Tagashira, E.; Hiramori, T.; Urano, T.; Nakao, K. and Yanaura, S. (1983): Effects of Propranolol on Barbital Dependence Formation and Withdrawal Signs. Jpn. J. Pharmacol., 33: 133-143.
19. Abdel-Zaher, A.; Hany, M.; Aly, S.; Abdel-Hady, R. and Abdel-Rahman, S. (2006): Alteration of Morphine Tolerence and Dependence by Aminoguanidine in Mice. Eur. $J$. Pharmacol., 450: 60-66.

20. Van Herck, H.; Baumans, V.; Van der Craats, N.; Hesp, A.; Meijer, G.; Van Tintelen, G.; Walvoort, $H$. and Beynen, $A$. (1992): Histological Changes in the Orbital Region of rats after Orbital Puncture. Lab. Anim., 26: 53-58.

21. Naderali, E.; Fatani, S. and Williams, G. (2004): Chronic Withdrawal of a High-Palatable Obesity-Inducing Diet Completely Reverses Metabolic and Vascular Abnormalities Associated with Dietary-Obsity in the Rat. Atherosclerosis, 172: 6369.

22. Sampaio, R.; Tams-Santos, J.; Melo, S.; Hyslop, S.; Franchini, K; Luca, I. and Moreno, $H$. (2002): Hypertension Plus Diabetes Mimics the Cardiomyopathy Induced by Nitric Oxide Inhibition in Rats. Chest, 122: 1412-1420.

23. Trinder, P. (1969): Determination of Blood Glucose Using 4-amino Phenazone as Oxygen Acceptor. J. Clin. Pathol., 22(2): 246.

24. Kim, S.; Wanibuchi, H.; Hamaguchi, A.; Miura, K.; Yamanaka, S. and Iwao, $H$. (1997): Angiotensin Blockade Improves Cardiac and Renal Complications of Type II Diabetic Rats. Hypertension, 30: 1054-1061. 
25. Clark, P. and Hales, C. (1994): How to measure Plasma Insulin. Diabetes Metab. Rev., 10: 79-90.

26. Roeschlau, P.; Bent, E. and Gruber, W. (1974): Enzymatic Determination of Total Cholesterol in Serum. Z. Klin. Chem. Klin. Biochem., 12: 226.

27. Burstein, M.; Scholnick, H. and Morfin, R. (1970): Rapid Method for the Isolation of Lipoproteins from Human Serum by Precipitation with Polyanions. J. Lipid Res., 11: 583-595.

28. Lopes-Virella, M.; Stone, P.; Ellis, S. and Colwell, J. (1977): Cholesterol Determination in High-Density Lipoproteins Separated by Three Different Methods. Clin. Chem., 23: 882884.

29. Friedewald, W.; Levy, R. and Fridrickson, D. (1972): Estimation of the Concentration of Low-Density Lipoprotein Cholesterol in Plasma, without Use of the Preparative Ultracentrifuge. Clin. Chem., 18: 499-502.

30. Bucolo, G. and David, $H$. (1973): Ouantitative Determination of Serum Triglycerides by the use of Enzymes. Clin. Chem., 19: 476482.

31. Buege, J. and Aust, S. (1978): Microsomal Lipid Peroxidation. Methods Enzymol., 52: 302-310.

32. Nishikimi, M.; Appaji, N. and Yagi, K. (1972): The Occurrence of Superoxide Anion in the Reaction of Reduced Phenazine Methosulfate and Molecular Oxygen. Biochem. Biophys. Res. Commun., 46: 849-854.
33. Aebi, H. (1984): Catalase in vivo. Methods Enzymol., 105: 121-126.

34. Sun, J.; Zhang, X.; Broderick, $M$. and Fein, H. (2003): Measurement of Nitric Oxide Production in Biological systems by Using Griess Reaction Assay. Sensors, 3: 276-284.

35. Zimmer, P.; Alberti, K. and Shaw, J. (2001): Global and Societal Implication of the Diabetes Epidemic. Nature, 414: 782-787.

36. Cooke, D. (2004): Diabetes. In: Encyclopedia of Bioloical Chemistry; Lennarz, J. and Lane, M.(eds); pp 582-592, Elsevier Inc.

37. Meigs, J. (2003): Epedimiology of Cardiovascular Complications in Type 2 Diabetes Mellitus. Acta Diabetol., 40(Suppl. 2): S358S361.

38. Kasuga, M. (2006): Insulin Resistance and Pancreatic Beta Cell Failure. J. Clin. Invest., 116: 1756-1760.

39. Goldstein, B. (2002): Insulin Resistance as the Core Defect in Type 2 Diabetes Mellitus. Am. $\boldsymbol{J}$. Cardiol., 90: 3G-10G.

40. Book, W. (2002): Carvedilol: A Nonselective Beta Blocking Agent with Antioxidant Properties. Congest. Heart Fail., 8: 173-190.

41. Mac, I. and Weglicki, W. (2004): Potent Antioxidant Properties of 4-HydroxylPropranolol. J. Pharmacol. Exp. Ther., 308: 85-90.

42. Stoppa, G.; Cesquini, M.; Roman, E.; Ogo, S. and Torsoni, M. (2006): Aminoguanidine Prevented Impairment of Blood Antioxidant 
System in Insulin-Dependant Diabetic Rats. Life Sci., 78: 1352-1361.

43. Jacob, S.; Balletshofer, B.; Henriksen, E.; Volk, A.; Mehnert, B.; Loblein, K.; Haring, H. and Rett, K. (1999): Beta-Blocking Agents in Patients with Insulin Resistance: Effects of Vasodilating Beta-Blockers. Blood Press., 8: 261-268.

44. Ruivo, G.; Leandro, S.; do Nascimento, C.; Catanozi, S.; Rocha, J.; Furukawa, L.; Dolnikoff, M.; Quintao, E. and Heimann, J. (2006): Insulin Resistance Due to Chronic Salt Restriction Is Corrected by Alpha and Beta Blockkade and by LArginine. Physiol. Behav., 88: 364-370.

45. Gonzalez-Feldman, E. (2005): Carvedilol, Metoprolol, and Insulin Resistance. J. A. M. A., 293: 1190.

46. Bhat, P.; Makwana, D.; Santani, D. and Goyal, R. (2007): Comparative Effectiveness of Carvedilol and Propranolol on Glycemic Control and Insulin Resistance Associated with L-Thyroxin-Induced HyperthyroidismExperimental Study. Can. J. Physiol. Pharmacol., 85: 514520.

47. Lang, C. (1993): BetaAdrenergic Blockade Attenuates Insulin Resistanc Induced by Tumor Necrosis Factor. Am. J. Physiol., 264: R984-R991.

48. Kwon, G.; Xu, G.; Marshall, C. and McDaniel, M. (1999): Tumor Necrosis Factor AlphInduced Pancreatic Beta -Cell Insulin Resistance is Mediated by Nitric Oxide and Prevented by
15-Deoxy-Delta 12,14-Prostaglandin $\mathrm{J}_{2}$ and Aminoguanidine. A Role for Peroxisome Proliferator-Activated Receptor Gamma Activation and Inos Expression. J. Biol. Chem., 274: 18702-18708.

49. Asbrink, S.; Zickert, A.; Gyllenhammar, H. and Palmblad, J. (2000): No Effect of Carvedilol on Nitric Oxide Generation in Phagocytes but Modulation of Production of Superoxide Ions. Biochem. Pharmacol., 59: 1007-1013.

50. Moule, S. and Denton, $R$. (1998): The Activation of P38 MAPK by the Beta-Adrenergic Agonist Isoproternol in Rat Epididymal Fat Cells. F.E.B.S. Lett., 439: 287-290.

51. Giugliano, D.; Acampora, R.; DeRosa, N.; Ziccardi, P.; Ragone, R.; DeAngelis, L. and D'Onofrio, F. (1997): Metabolic and Cardiovascular Effects of Carvedilol and Atenolol in NonInsulin-Dependant Diabetes Mellitus and Hypertension. A Randomized, Controlled, Trial. Am. J. Intern. Med., 126: 955959.

52. Bakris, G.; Fonseca, V.; Katholi, R.; McGill, J.; Phillips, R.; Raskin, P.; Wright, J.; Oakes, R.; Lukas, M.; Andrson, K. and Bell, D. (2004): Metabolic Effects of Carvedilol Vs Metoprolol in Patients with Type 2 Diabetes Mellitus and Hypertension: A Randomized Controlled Trial. J.A. M. A., 292: 2227-2236.

53. Uzunlulu, M.; Oguz, A. and Yorulmaz, E. (2006): The Effects of Carvedilol on Metabolic Parameters in Patients 
with Metabolic Syndrome. Int. Heart J., 47: 421-430.

54. Goto, Y.; Tamachi, H.; Fusegawa, Y.; Kakaya, N.; Homma, Y.; Mikami, M; Ioris, S. and Yamazaki, A. (1991): Effects of Carvedilol on Serum Lipids in Patients with Essential Hypertension. J. Cardiovasc. Phrmacol., 18(Suppl. 4): S45S50.

55. Cheng, J.; Kamiya, K. and Kodama, I. (2001): Carvedilol: Mollecular and Cellular Basis for its Multifaceted Therapeutic Potential. Cardiovsc. Drug Rev., 19: 152-171.

56. Kim, W.; Jeong, M.; Cha, K.; Hyun, D.; Hur, S.; Kim, K.; Hong, Y.; Park, H.; Kim, J.; Ahn, Y.; Kim, M.; Cho, J.; Park, J.; Park, J.C. and Kang, J. (2005): Effect of AntiOxidants (Carvedilol and Probucol) Loaded Stents in a Porcine Coronary Restenosis Model. Circ. J., 69: 101-106.

57. Park, J.; Ha, H.; Kim, M.; Ahn, H.; Huh, K. and Kim, Y. (2006): Carvedilol Inhibits Platelet-Derived Growth FactorInduced Extracellular Matrix Synthesis by Inhibiting Cellular Reactive Oxygen Species and Mitogen-Activated Protein Kinase Activation. J. Heart Lung Transplant., 25: 683-689.

58. Du, X.; Edelstein, D.; Rossetti, L.; Fantus, I.; Goldberg, H.; Ziyadeh, F.; Wu, J. and Brownlee, M. (2000): Hyperglycemic-Induced Mitochondrial Superoxide Over- production Activates the Hexosamine Pathway and Induces Plasminogen Activator Inhibitor-1 Expression by Increasing Spl Glycosylation. Proc. Natl. Acad. Sci. U.S.A., 97: 12222-12226.

59. Marechal, A.; Mattioli, T.; Stuehr, D. and Santolini, J. (2007): Activation of Peroxynitrite by Inducible NitricOxide Synthase: A Direct Source of Nitrative Stress. J. Biol. Chem., 282: 14101-14112.

60. Tang, W.; Lopez, F.; Lo, S.; Yee, Y.; Mullin, A.; Zhang, Y. and Fowler, M. (2003): Influence of Carvedilol Therapy on Myocardial Expression of Inducible Nitric Oxide Synthase (NOS2) and the Contractile Response to Inotropic Stimulation in Patients with Dilated Cardiomyopathy. J. Cardiac Failure, 9: S34.

61. Pu, J.; Chen, G.; Zhang, C. and Wang, L. (2004): Carvedilol Regulated Activity of Nitric Oxide Synthase Isoforms in Atherosclerotic Rabbits Induced by Cholesterol and Ballon Injury. Cardiovsc. Pathol., 13: S139S200.

62. Grimm, D.; Jabusch, H.; Kossmehl, P.; Huber, M.; Fredersdrof, S.; Griss, D.; Kramer, B. and Kromer, E. (2002): Experimental Diabetes and Left Ventricular Hypertrophy: Effects of BetaReceptor Blockade. Cadiovsc. Pathol., 11: 229-237. 


\title{
تأثير الكارفيدولول الواقي للقب في الفئران البيضاء المريضة بالنوع الثاني من البوال السكري
}

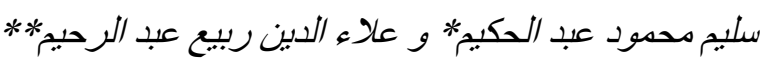

من قسمي الفسيولوجي * و الأمر اض الباطنية ** - كلية الطب عبد - جامعة المنيا

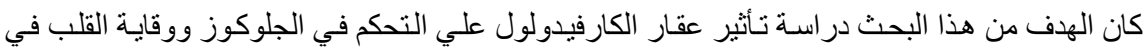

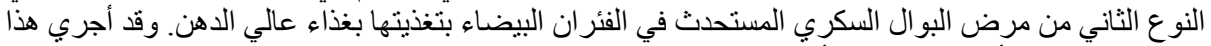

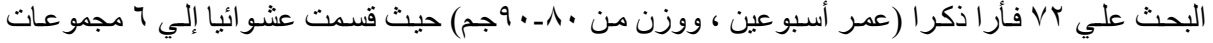

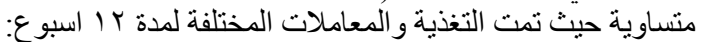

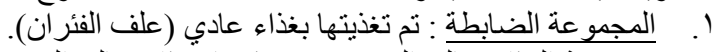

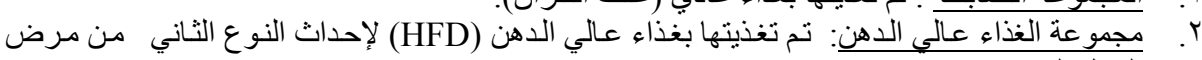

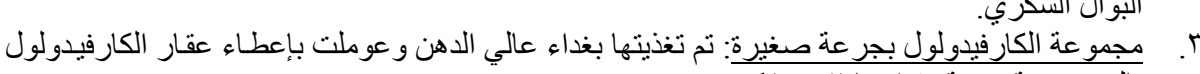

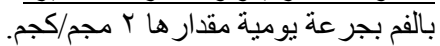

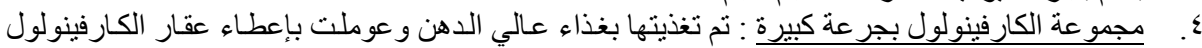

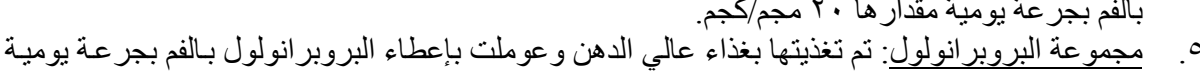
مقدار ها · ب مجم /كجم.

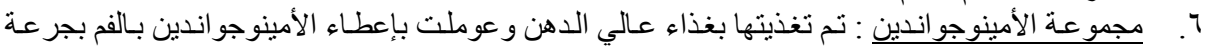

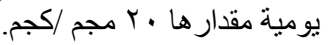

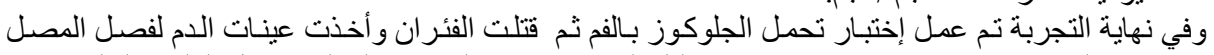

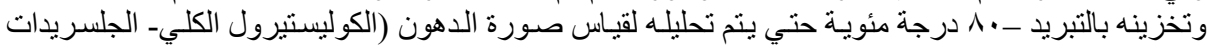

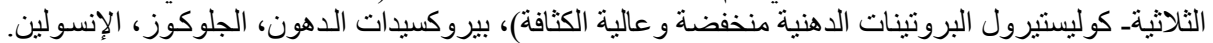

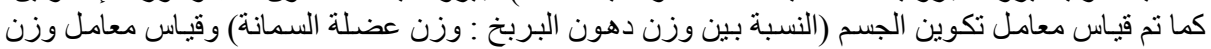

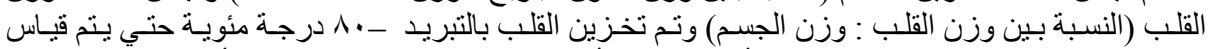

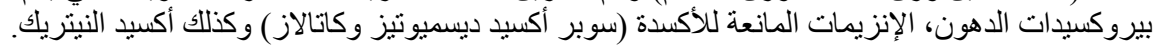

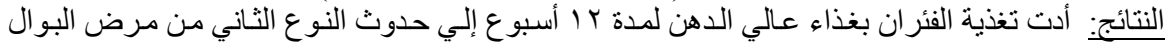

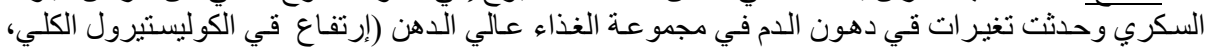

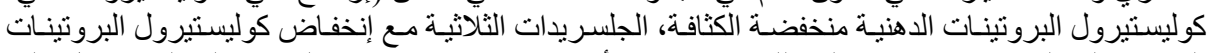

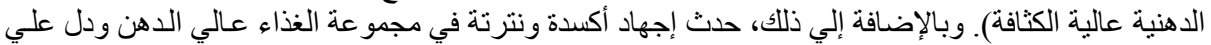

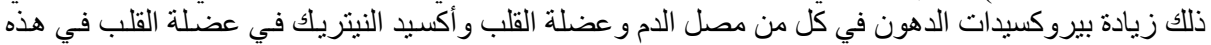

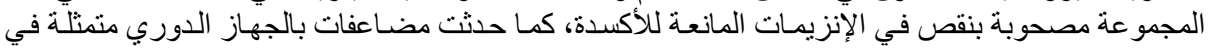
زيادة معامل وزن القعاء القبل

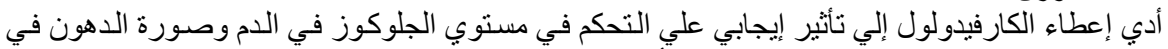

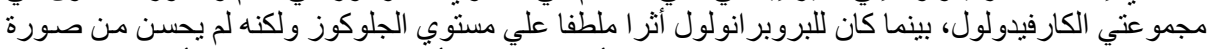

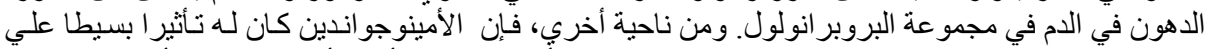

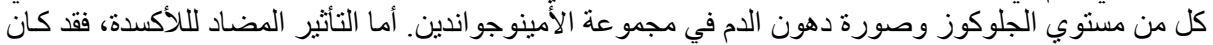

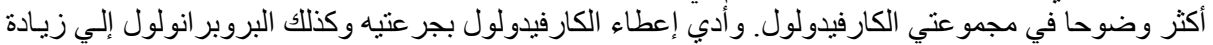

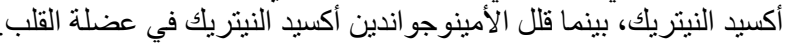

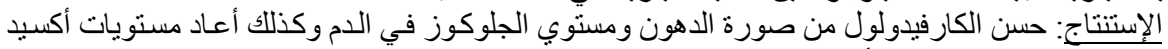

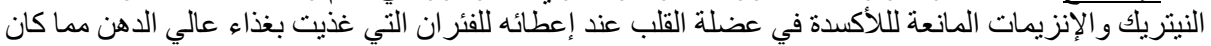

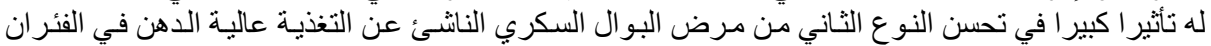
البيضاء ـ وقد تسأهم هذه التأثير ات في حماية القلب. 